\title{
Komitmen Organisasi dengan Organizational Citizenship Behavior pada Karyawan
}

\section{Organizational Commitment with Organizational Citizenship Behavior in Employees}

\author{
Doli Maulana Gama Samudera Lubis* \\ Fakultas Psikologi, Universitas Medan Area, Indonesia
}

Disubmit: 31 Oktober2021; Diproses: 31 Oktober2021; Diaccept: 23 November 2021; Dipublish: 02 Desember2021

*Corresponding author: E-mail: dolilubis@gmail.com

\begin{abstract}
Abstrak
Penelitian ini bertujuan untuk mengetahui hubungan antara komitmen organisasi dengan perilaku kewargaan organisasional (OCB) pada karyawan. Populasi dalam tinjauan ini lebih dari 260 orang diambil dari perwakilan yang masih bekerja efektif. Penelitian ini menggunakan metode kuantitatif dan pemeriksaan dalam tinjauan ini dengan strategi pemeriksaan purposive berjumlah 100 orang. Instrumen yang digunakan adalah jajak pendapat komitmen organisasional dengan Organizational Citizenship Behavior (OCB). Penelitian dibedah menggunakan tes Analisis Regresi. Hasil penelitian menunjukkan bahwa terdapat hubungan positif $\mathrm{Rx}-\mathrm{y}=0,589$ komitmen organisasi dengan perilaku kewargaan organisasi. Hal ini ditunjukkan dengan thitung $=4,194>$ ttabel $=1,985$ dengan nilai kepentingan $0,000<0,05$.
\end{abstract}

Kata Kunci: Komitmen Organisasi; Organizational Citizenship Behavior

\begin{abstract}
This study means to decide the connection between organizational commitment and organizational citizenship behavior (OCB) in employees. The populace in this review upwards of 260 taken from representatives who are still effectively working. The study utilized a quantitative methodology and the inspecting in this review with purposive examining strategy added up to 100 individuals. The instrument utilized is an organizational commitment poll with organizational citizenship behavior (OCB). The study was dissected utilizing the Regretion Analysis test. The outcomes showed that there was a positive relationship $R x-y=0.589$ of organization commitment with organizational citizenship behavior. This is shown by tcount $=4.194>$ ttable $=1.985$ with an importance worth of $0.000<0.05$.
\end{abstract}

Keywords: Organizational Commitment, Organizational Citizenship Behavior

Rekomendasi mensitasi :

Lubis, D.M.G.S. 2021, Komitmen Organisasi Dengan Organizational Citizenship Behavior pada Karyawan. Jurnal Penelitian Pendidikan, Psikologi dan Kesehatan(JP3K), 2 (3): 316-324. 


\section{PENDAHULUAN}

Perubahan lingkungan bisnis sangat cepat dan dan bersifat sangat tidak pasti mengharuskan organisasi-organisasi yang ada dalam suatu sektor industri untuk senantiasa meningkatkan efektifitas, efisiensi, dan kreatifitas (Bogler \& Somech, 2005). Peningkatan efektifitas, efisiensi dan kreatifitas ini sangat bergantung pada kesediaan karyawan untuk berkontribusi secara positif dalam menyikapi perubahan (Bogler \& Somech, 2005). Perilaku untuk bersedia memberi kontribusi positif pekerja ini diharapkan tidak hanya terbatas dalam kewajiban kerja secara formal, melainkan idealnya lebih dari kewajiban formal (Bowler \& Brass, 2003). Dalam literatur organisasi modern, perilaku dalam bentuk kerelaan untuk memberi kontribusi yang lebih dari kewajiban formal bukanlah merupakan bentuk perilaku organisasi yang dapat dimunculkan melalui bisnis kewajibankewajiban formal karyawan yang akhirnya menyebut perilaku ini sebagai Organizational Citizenship Behavior (Ahdiyana, 2010).

Kemampuan pekerja untuk mengambil bagian dalam asosiasi umumnya bergantung pada tujuan apa yang harus mereka capai dengan bergabung dengan asosiasi yang dimaksud. Komitmen pekerja terhadap asosiasi akan semakin tinggi jika asosiasi dapat memberikan apa yang dibutuhkan pekerja. Secara keseluruhan, kemampuan pekerja untuk menambah lingkungan kerja sangat dipengaruhi oleh keinginan organisasi untuk memenuhi tujuan dan keinginan pekerjanya.

Fenomena yang dimiliki karyawan Rumah Sakit Pertamina Pangkalan
Brandan setelah dilakukannya observasi ialah mereka dapat terus-menerus mengerjakan pekerjaan tambahan, dimana karyawan menunjukkan perilaku inovatif dan tidak terbatas di luar gambaran pekerjaan yang diberikan untuk mencapai tujuan, diantaranya menggabungkan diri dengan mitra kerja yang siap membantu, memberi ide-ide berharga untuk kemajuan pelaksanaan divisi atau organisasi sebagai aturan umum, bekerja pada kapasitas tertinggi dengan yang dibutuhkan oleh asosiasi, dan membangun lingkungan yang layak untuk organisasi di masyarakat luar.

Penelitian sebelumnya pun memberikan hasil bahwa salah satu hal yang mendasari karyawan bertahan dalam suatu organisasi karena adanya ikatan afektif terhadap organisasi (Khairuddin, 2018). Robbins \& Judge (2013), menjelaskan bahwa perilaku yang menjadi tuntutan perusahaan saat ini tidak hanya perilaku in-role, tetapi juga perilaku ekstrarole. Perilaku ekstra-role ini yang biasa dikenal dengan sikap kewargaan organisasi disebut dengan istilah organizational citizenship behavior (Oguz, 2010).

Organizational Citizenship Behavior (OCB) adalah perilaku yang disengaja dari seorang karyawan untuk menyelesaikan tugas atau pekerjaan diluar kewajiban atau komitmennya untuk kemajuan dan keuntungan dari perusahaannya (Waspodo \& Minadaniati, 2012). Artinya, karyawan dengan tingkat OCB tinggi bersedia untuk tidak dibayar menggunakan uang tunai atau imbalan tertentu, melainkan pada perilaku sosial setiap pekerja untuk bekerja melewati apa yang umumnya diinginkan oleh organisasi, diantaranya membantu mitra 
kerja saat istirahat tanpa pamrih (Garay, 2008).

Organ dkk. (Organ, Podsakof, \& Mackenzie, 2009) mencirikan perilaku kewargaan organisasional (OCB) sebagai perilaku individu yang bebas, dan tidak langsung menerima imbalan dari sistem hadiah konvensional, namun secara umum dapat memperluas kecakapan dan keefektifan kapasitas fungsi asosiasi. Tindakan perilaku kewargaan organisasi sifatnya bebas dan tanpa paksaan, sebab tindakan tersebut tidak diwajibkan oleh prasyarat pekerjaan atau serangkaian tanggung jawab yang secara jelas diperlukan oleh kontrak dengan perusahaan, tetapi sebagai keputusan individu.

Di dunia kerja dewasa ini, dimana pekerjaan semakin banyak dilakukan dalam kelompok dan memerlukan kemampuan beradaptasi, perusahaan membutuhkan pekerja yang memiliki perilaku kewargaan organisasi, yakni menolong orang lain dalam kelompok, menawarkan diri atau memilih untuk menyelesaikan tugas tambahan, menghindari bentrokan dengan mitra kerja, tunduk pada pedoman aturan, dan meminimalisir kemalangan dan gangguan yang berkaitan dengan tugas dan tanggung jawab (Robbins \& Judge, 2013).

Perilaku

Kewarganegaraan Organisasional (OCB) selain dikenal sebagai perilaku pekerjaan tambahan (the extra-role behavior) (Noe, Hollenbeck, Gerhart, \& Wright, 2011) ialah merupakan salah satu hal penting untuk kelangsungan hidup perusahaan. Perihal ini juga diungkapkan oleh Katz dan Kahn (Hendrawan, Sucahyawati, \& Indriyani, 2017) yang mengakui tiga klasifikasi perilaku karyawan yang penting untuk mewujudkan perusahaan yang efektif, yaitu karyawan harus masuk dan tetap dalam suatu perusahaan, mereka diwajibkan menyelesaikan tugas dan kewajiban tertentu di posisi tertentu, mereka harus disibukkan dengan latihan kreatif dan inovatif terlebih lagi untuk melampaui pandangan kebutuhan pekerjaannya. Klasifikasi terakhir adalah hal yang dikenal sebagai Organizational Citizenship Behavior. Perilaku kewargaan organisasi ini tidak bisa dipisahkan dari komitmen organisasi yang dimiliki pekerja kepada perusahaannya, sebab seluruh pelaksanaan pekerjaan yang melampaui apa yang telah ditentukan, umumnya dipengaruhi oleh kuat atau tidaknya komitmen karyawan terhadap organisasi tempat dirinya bekerja (Smith, Organ, \& Near, 1983).

Perilaku karyawan yang dilakukan dengan senang hati, tulus dan sukarela tanpa harus dikendalikan dan diperintah oleh perusahaan dalam melakukan pelayanan dengan baik disebut dengan organizational citizenship behavior (OCB) (Organ, Podsakoff, \& MacKenzie, 2006). Rendahnya komitmen di dalam suatu organisasi menunjukkan kurangnya tanggung jawab seorang karyawan dalam melaksanakan pekerjaannya. Komitmen organisasi yang dimiliki para pegawai menjadi semakin sulit untuk diterapkan sebab semakin banyak perusahaan yang menerapkan sistem kontrak kepada para pegawai (Wahyudi \& Sudibya, 2016).

Komitmen organisasional menurut Luthans (Luthans, 2011) adalah sikap loyal pekerja dan dilakukan berkelanjutan dari individu yang merupakan bagian organisasi untuk menunjukkan kepedulian mereka untuk pencapaian sukses dan integritas 
perusahaan. Sifat loyal ini ditunjukkan oleh tiga hal, khususnya:

1. Dorongan kuat seorang individu untuk bertahan sebagai bagian dari organisasi yang diikutinya;

2. Keinginan untuk menginvestasikan sejumlah energinya untuk organisasi tempatnya bernaung;

3. Memiliki keyakinan yang kuat dan menerima atas nilai dan tujuan organisasi.

Pekerja yang memiliki komitmen organisasi tinggi akan lebih banyak bekerja, lebih sering ingin menolong dan bisa berkoordinasi dengan rekan kerja lainnya. Satu masalah lagi diidentifikasi dengan komitmen organisasi pekerja ialah karyawan tidak mempunyai tanggung jawab kerja yang solid, hal ini tampak dari perilakunya. Karyawan masih sering menunggu arahan dari atasan, meskipun faktanya bahwa semua karyawan telah menerima penjelasan deskripsi pekerjaan yang jelas sesuai dengan posisi jabatannya. Namun, masih banyak karyawan yang tidak dapat menyelesaikan tugas dan tanggung jawabnya sesuai deadline yang diberikan padanya.

Penggambaran di atas menunjukkan betapa pentingnya komitmen organisasi yang merupakan mentalitas yang ditampilkan secara resmi, emosional dan ingin cukup mampu untuk tetap berada dalam lingkungannya dan perilaku kewargaan organisasi yang merupakan perilaku extra-role karyawan dimana pekerjaan tambahan yang aksesibilitas dikerjakan oleh karyawan melewati pekerjaan atau tugas yang diharuskan dan tidak langsung merasakan kerangka hadiah.
Berdasarkan paparan tersebut, maka peneliti tertarik untuk meneliti tentang hubungan komitmen organisasi dengan organizational citizenship behavior agar dapat memberikan gambaran mengenai eratnya hubungan kedua variabel tersebut.

\section{METODE PENELITIAN}

Dalam penelitian ini, metode yang digunakan yaitu metode penelitian kuantitatif. Jenis penelitian kuantitatif yang digunakan adalah korelasional, dimana penelitian ini bersifat menanyakan hubungan antara dua variabel atau lebih (Sugiyono, 2010).

Penelitian ini dilaksanakan di Rumah Sakit Pertamina Pangkalan Brandan dengan jumlah subjek sebanyak 100 orang menggunakan teknik simple random sampling. Skala disusun berdasarkan skala likert dengan empat pilihan jawaban. Data diolah dengan komputer menggunakan program SPSS 23.0 for windows.

Skala komitmen organisasi disusun berdasarkan dimensi yang dikemukakan oleh Allen dan Meyer (2004) yaitu affective commitment, continuance commitment dan normative commitment yang berjumlah 21 aitem dengan indeks reliabilitas Cronbach's Alpha sebesar 0,906 . Skala organizational citizenship behavior (OCB) disusun berdasarkan aspek yang diungkapkan oleh Organ, Podsakof dan Mackenzie (2009) yaitu altruism, conscientiousness, sportmanship, courtessy dan civic virtue yang berjumlah 27 aitem dengan indeks reliabilitas Cronbach's Alpha sebesar 0,923. 


\section{HASIL DAN PEMBAHASAN}

Berdasarkan pengujian normalitas sebaran data menggunakan analisis Kolmogorov Smirnov pada Program SPSS untuk komitmen organisasi dan organizational citizenship behavior (OCB) diketahui bahwa variabel tersebut memiliki sebaran data normal mengikuti prinsip kurva normal, hal tersebut dapat dilihat pada tabel 1 .

Tabel 1: Normalitas Data

\begin{tabular}{llll}
\hline Variabel & K-S & Sig (p) & Keterangan \\
\hline $\begin{array}{l}\text { Komitmen } \\
\text { Organisasi } \\
\text { Organizaional }\end{array}$ & 1,065 & 0,206 & Normal \\
$\begin{array}{l}\text { Citizenship } \\
\text { Behavior }\end{array}$ & 1,163 & 0,134 & Normal \\
\hline
\end{tabular}

Sumber: Hasil Analisis SPSS

Setelah diketahui variabel penelitian memiliki sebaran data normal, selanjutnya dilakukan analisis data untuk melihat hubungan antara kedua variabel tersebut. Hasil penelitian dapat dilihat pada tabel 2 di bawah ini.

Tabel 2: Hasil Uji Correlations

\begin{tabular}{|c|c|c|c|}
\hline & & OCB & $\begin{array}{l}\text { Komitmen } \\
\text { Organisasi }\end{array}$ \\
\hline \multirow{3}{*}{$\begin{array}{l}\text { Pearson } \\
\text { Correlations }\end{array}$} & OCB & 1,000 & .589 \\
\hline & $\begin{array}{l}\text { Komitmen } \\
\text { Organisasi }\end{array}$ & .589 & 1,000 \\
\hline & OCB & ${ }^{\circ}$ & .000 \\
\hline \multirow[t]{2}{*}{ Sig (1-tailed) } & $\begin{array}{l}\text { Komitmen } \\
\text { Organisasi }\end{array}$ & .000 & 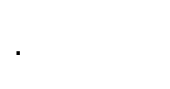 \\
\hline & OCB & 100 & 100 \\
\hline $\mathrm{N}$ & $\begin{array}{l}\text { Komitmen } \\
\text { Organisasi }\end{array}$ & 100 & 100 \\
\hline
\end{tabular}

Sumber: Hasil Analisis SPSS

Hasil penelitian mengungkapkan adanya hubungan Komitmen Organisasi dengan Perilaku Kewargaan Organisasi $\mathrm{R}_{\mathrm{x} 2 \mathrm{y}} \mathrm{y}$ sebesar 0,589 dengan $\mathrm{p}=0,000<$ 0,05 . Nilai tersebut berarti bahwa terdapat hubungan yang signifikan antara komitmen organisasi dengan OCB sebesar 0,589 . Artinya, variabel OCB dijelaskan oleh variabel komitmen organisasi sebesar $58,9 \%$.

Adapun hasil penelitian ini sama, berkaitan dan didukung oleh penelitian terdahulu yakni diteliti oleh Yohanas Oemar Fakultas Ekonomi Universitas Riau Pekanbaru (Oemar, 2013). Populasi dalam penelitian adalah PNS di lingkungan Bappeda Kota Pekanbaru sejumlah 56 orang. Penelitian ini menggunakan metode sensus untuk mendapatkan sampel sejumlah 56 orang. Pengujian hipotesis menggunakan tes statistikal yaitu analisis regresi berganda. Pengujian kelayakan model diperoleh dari nilai $\mathrm{R}$ Square yang disesuaikan sebesar 0,625, yang artinya sebanyak $62,5 \%$ varian OCB PNS itu dapat dijelaskan dari pengujian varian tiga variabel bebas yaitu budaya organisasi, kemampuan bekerja dan komitmen organisasi. Sementara 37,5\% lainnya dijelaskan di luar model. Dari hasil pengujian kausalitas didapatkan dengan cara mengamati hasil dari signifikansi budaya organisasi, kemampuan bekerja dan komitmen organisasi terhadap variabel OCB dengan tingkat kepercayaan 99\%.

Terdapat tiga faktor yang mempengaruhi komitmen organisasional (Allen \& Meyer, 2004), yaitu:

1. Karakteristik pribadi individu.

Karakteristik individu dibagi menjadi 2 variabel, yakni variabel demografis serta variabel disposisional. Variabel demografis melingkupi jenis kelamin, umur, status pernikahan, tingkat pendidikan, dan lamanya seseorang bekerja pada suatu organisasi. Sedangkan variabel disposisional mencakup kepribadian dan nilai yang dimiliki anggota organisasi. Variabel disposisional ini memiliki hubungan 
yang lebih kuat dengan komitmen berorganisasi, karena adanya perbedaan pengalaman masin-masing anggota dalam organisasi tersebut.

2. Karakteristik organisasi.

Yang termasuk dalam karakteristik organisasi yaitu: struktur organisasi, desain kebijaksanaan dalam organisasi serta bagaimana kebijakan tersebut diterapkan.

3. Pengalaman organisasi.

Yang termasuk dalam pengalaman organisasi ialah peran, kepuasan serta motivasi anggota kelompok selama berpartisipasi di kelompoknya, begitu pula dengan ikatan antar rekan di kelompok bersama atasannya.

Menurut Gary Dessler, metode yang dapat digunakan untuk menumbuhkan dan membangun komitmen organisasi pada diri individu ialah sebagai berikut (Sopiah, 2008):

1. Make it charismatic.

Menganggap visi dan misi perusahaan sebagai suatu yang memikat, suatu hal yang digunakan sebagai pijakan, alasan untuk setiap pegawai dalam bertingkah laku, bersikap dan bertindak.

2. Build the tradition.

Semua yang baik dan dapat diterima dalam suatu organisasi sebaiknya dijadikan kebiasaan yang harus dilestarikan, terus dipelihara oleh generasi masa depan.

3. Have comprehensive grievance procedures.

Bilamana terdapat protes dari luar maupun dalam ke pihak perusahaan, maka pihak asosiasi harus mempunyai strategi guna mengelola protes ini sepenuhnya.
4. Provide extensive two way communications.

Bangun dan menjalin komunikasi dua arah dalam asosiasi tanpa menganggap sepele orang yang jabatannya di bawah kita.

5. Create a sense of community.

Buatlah seluruh komponen dalam asosiasi sebagai sebuah komunitas dimana terdapat di dalamnya nilai kebersamaan, perasaan memiliki, partisipasi, rasa berbagi, dan seterusnya.

6. Build value homogenety.

Membangun nilai-nilai berdasarkan kemiripan. Setiap individu dari organisasi mempunyai peluang yang sama, misalnya untuk promosi. Premis yang digunakan untuk promosi ialah kapasitas, keahlian, minat, motivasi, eksekusi, dengan tidak adanya perilaku pemisahan.

7. Share and share alike.

Organisasi atau perusahaan seharusnya membuat pengaturan dimana pekerja dari tingkat bawah hingga ke tingkat yang paling tinggi tidak memiliki perbedaan yang terlalu ekstrim atau jelas dalam pemberian upah, lifestyle, penampilan fisik, dan seterusnya.

8. Emphasize barnraising, cross utilization and teamwork.

Organisasi sebagai sebuah komunitas diharapkan saling kerja sama, berbagi, memberikan bantuan dan kebebasan yang setara di asosiasi. Contohnya, penting untuk melakukan pertukaran dalam sebuah asosiasi agar individu yang bekerja di luar ruangan dapat ditempatkan untuk bekerja di dalam ruangan. Seluruh asosiasi adalah 
kelompok kerja. Masing-masing dari mereka diharapkan memberikan kinerja tingkat atas untuk pencapaian organisasi.

9. Get together.

Selenggarakan acara yang mencakup seluruh individu dari kelompok asosiasi agar tercipta kesempatan untuk menjalin harmoni dan kebersamaan. Seperti, sesekali proses pembuatan produk dihentikan dan seluruh pekerja ikut di kesempatan olahraga ataupun rekreasi dengan keluarga, permainan dan sebagainya yang diselesaikan oleh semua individu dari asosiasi dan keluarga mereka.

10. Support employee development.

Studi terdahulu mengungkapkan hasil bahwa pekerja akan lebih berdedikasi untuk asosiasi jika asosiasi ini berfokus pada peningkatan jabatan dan pengetahuan dalam jangka panjang.

11. Commit to actualizing.

Tiap pegawai ditawarkan kesempatan yang seimbang untuk menampilkan dan mewujudkan diri mereka sepenuhnya dalam asosiasi dengan batasan masing-masing.

12. Provide first year job challenge.

Ketika memasuki sebuah asosiasi, individu membawa mimpinya, harapan dan keinginan mereka. Berikan bantuan nyata kepada individu tersebut guna menumbuhkan kapasitas laten mereka serta mewujudkan fantasi mereka.

13. Enrich and empower.

Menciptakan kondisi dengan tujuan agar pegawai tidak bekerja dengan monoton sebab jadwal yang terus berulang akan membuat sensasi kelelahan dan kebosanan bagi pegawai. Rutinitas yang monoton ini tidak dapat dibiarkan dengan alasan bahwa itu akan mengurangi kinerja pegawai.

14. Promote from within.

Dalam hal penerimaan pegawai baru, peluang utama harus diberikan pada pegawai magang di organisasi sebelum mencari kandidat dari luar perusahaan.

15. Provide developmental activities.

Bilamana perusahaan memutuskan strategi untuk menerima pegawai melalui pihak intern sebagai keutamaan, akibatnya akan mendorong pegawai untuk lanjut mengembangkan diri dan posisi jabatan mereka.

16. The question of employee security.

Apabila pegawai merasa memiliki keamanan secara mental dan fisik, maka pada diri pegawai tersebut akan muncul tanggung jawab untuk berdedikasi tanpa adanya dorongan dari orang lain.

17. Commit to people first values.

Rasa komitmen organisasi pada diri pekerja adalah tidak mudah dimana membutuhkan waku interaksi yang lama dan tak dapat dibingkai dalam sekejap. Sehingga baiknya organisasi dapat memperlakukan pekerja sebaikbaiknya dan secara tepat disaat awal dimulainya pekerja memasuki organisasi. Sehingga, pekerja akan memiliki kesan positif kepada perusahaan.

18. Put in writing.

Informasi tentang peraturan, misi, visi, selogan, filosofi, sejarah, sistem, dan sebagainya yang dimiliki asosiasi 
harus diatur dialam bentuk catatan tulis dan bukan hanya secara verbal.

19. Hire right-kind manager.

Apabila pemimpin mengenalkankan nilai, budaya, aturan, disiplin, dan seterusnya kepada bawahannya, maka diharapkan para pemimpin tersebut harus menampilkan perilaku model sebagai bahan teladan dalam bersikap setiap hari.

20. Walk the talk.

Perilaku tidak dapat disangkal sebagai lebih layak daripada hanya kata-kata. Jika para pemimpin menginginkan pekerjanya untuk mencapai sesuatu, pada saat itu, pemimpin pun harus mulai melakukan sesuatu, bukan hanya bicara.

\section{SIMPULAN}

Berdasarkan hasil dan penjelasan yang telah dipaparkan, dapat diperoleh kesimpulan dimana ada hubungan yang signifikan antara komitmen organisasi dan perilaku kewargaan organisasi (OCB) pada karyawan Rumah Sakit Pertamina Pangkalan Brandan dengan persentase sebesar 58,9\%. Angka ini menunjukkan bahwa semakin tinggi nilai komitmen organisasi, semakin tinggi juga tingkat perilaku kewargaan organisasi.

\section{DAFTAR PUSTAKA}

Ahdiyana, M. (2010). Dimensi Organizational Citizenship Behavior (OCB) dalam Kinerja Organisasi. Jurnal Efisiensi , 1-10.

Allen, N. J., \& Meyer, J. P. (2004). TCM Employee Commitment Survey:Academic Users Guide 2004. The University of Western Ontario: Department of Psychology .

Bogler, R., \& Somech, A. (2005). Organizational Citizenship Behavior in School. How Does it Relate to Participation in Decision Making? Journal of Educational Administration , 420438.
Bowler, \& Brass. (2003). Relationship and Interpersonal Citizenship Behavior: A Social Network Perspective On Organizational Citizenship Behavior. International Sunbelt Social Network Conference. Mexico: www.insna.org.

Garay, H. D. (2008). Kinerja Extra-Role dan Kebijakan Kompensasi. SINERGI, Kajian Bisnis dan Manajemen .

Hendrawan, A., Sucahyawati, H., \& Indriyani. (2017). Organizational Citizenship Behavior pada Karyawan Akademi Maritim Nusantara. Prosiding Seminar Nasional UNIMUS (hal. 39-48). Semarang: media.neliti.com.

Khairuddin. (2018). Gambaran Komitmen Organisasi dan Perilaku Kewargaan Organisasi. Jurnal Pendidikan Ilmu-Ilmu Sosial , 161-166.

Luthans, F. (2011). Organizational Behaviour: An Evidence-Based Approach 12th Edition. New York: McGraw-Hill.

Noe, R. A., Hollenbeck, J. R., Gerhart, B., \& Wright, P. M. (2011). Manajemen Sumber Daya Manusia: Mencapai Keunggulan Bersaing. Cetakan Kedua. Terjemahan: David Wijaya. Jakarta: Salemba Empat.

Oemar, Y. (2013). Pengaruh Budaya Organisasi, Kemampuan Kerja, dan Komitmen Organisasi terhadap Organizational Citizenhsip Behavior (OCB) Pegawai pada BAPPEDA Kota Pekanbaru. Jurnal Aplikasi Manajemen .

Oguz. (2010). The Relation Between The Leadership Style of The School Administrators and The Organizational Citizenship Behaviors of Teacher. Procedia Social and Behavioral Sciences, 1188-1193.

Organ, D. W., Podsakof, P. M., \& Mackenzie, S. B. (2009). Organizational Citizenship Behavior: Its Nature, Antecedents and Consequences. California: Sage Publication.

Organ, D. W., Podsakoff, P. M., \& MacKenzie, S. B. (2006). Organizational Citizenship Behavior: Its Nature, Antecedents, and Consequences. SAGE Publications.

Robbins, S. P., \& Judge, T. A. (2013). Organizational Behavior. Fifteenth Edition. New Jersey: Pearson Education Inc.

Smith, C. A., Organ, D. W., \& Near, J. P. (1983). Organization Citizenship Behavior. Its Nature and Antecendent. Journal of Applied Psychology , 653-663.

Sopiah. (2008). Perilaku Organisasional. Yogyakarta: Penerbit Andi.

Sugiyono. (2010). Metode Penelitian Pendidikan Pendekatan Kuantitatif, Kualitatif dan R\&D. Bandung: Alfabeta. 
Wahyudi, N. K., \& Sudibya, I. G. (2016). Pengaruh Kepuasan Kerja dan Komitmen Organisasional pada Kinerja Karyawan di Natya Hotel Kuta Bali. Jurnal Manajemen Unud , 870-897.

Waspodo, A. A., \& Minadaniati, L. (2012). Pengaruh Kepuasan Kerja dan Iklim Organisasi Terhadap Organizational Citizenship Behavior (OCB) Karyawan PT Trubus Swadaya Depok. Journal Riset Manajemen Sains Indonesia. 